\title{
Polytetrafluoroethylene valved conduits for right ventricle- pulmonary artery reconstruction: Do they outperform xenografts and allografts?
}

\author{
John W. Brown, MD
}

\footnotetext{
From the Division of Cardiothoracic Surgery, Department of Surgery, Indiana University School of Medicine, Indianapolis, Ind.

Disclosures: J.W.B. receives consultation fees from Medtronic, Inc, for consultation of the Contegra conduit and Harmony Percutaneous valves, and receives an honorarium from Cryolife, Inc, for speaking at annual company sponsored educational meeting concerning allografts used for Ross AVR.

Received for publication Jan 11, 2018; accepted for publication Jan 12, 2018; available ahead of print March 9, 2018.

Address for reprints: John W. Brown, MD, Division of Cardiothoracic Surgery, Department of Surgery, Indiana University School of Medicine, 545 Barnhill Drive, Indianapolis, IN 46202 (E-mail: jobrown@iupui.edu). J Thorac Cardiovasc Surg 2018; 155:2577-8 $0022-5223 / \$ 36.00$

Copyright (C) 2018 by The American Association for Thoracic Surgery https://doi.org/10.1016/j.jtcvs.2018.01.019
}

Miyazaki and Yamagishi ${ }^{1}$ are to be commended for their excellent polytetrafluoroethylene (PTFE) valved right ventricle-pulmonary artery (RV-PA) conduit clinical results, which are illustrated in this article.

Allografts and bovine jugular vein conduits have been the most popular RV-PA conduits in the United States and Europe for the last 2 decades. These conduits function well for a few years, and their durability has improved. However, their limited long-term durability necessitates multiple conduit exchanges over the patient's lifetime. Allografts generally are not available in Japan, and the bovine jugular vein conduit has become available only in the last 2 to 3 years. Japan's need for a right ventricular outflow tract reconstruction material stimulated their early interest in PTFE as a pulmonary valve substitute.

Yamagishi first demonstrated the use of 0.1-mm PTFE material, designed and developed for pericardial closure for making a synthetic pulmonary valve leaflet, and published its use as a monocusp valve in $1993 .^{2}$ We adopted and modified the monocusp technique 24 years ago and continue to use it for pulmonary valve reconstruction in patients requiring a transannular patch. Soon after their monocusp experience, Miyazaki and Yamagishi ${ }^{1}$ began making handmade conduits using 0.1-mm PTFE for leaflets and a thicker tubular PTFE for the conduit. They recently added sinuses and fan-shaped leaflets since 2010 based on hydrodynamic experiments in a pulse duplicator.

This article summarizes the outcomes of 902 patients with handmade PTFE valved conduits constructed by a single surgeon. The conduits included bulging sinuses and fan-shaped PTFE leaflets in 9 different sizes (8-24 $\mathrm{mm}$ in diameter) and were implanted in children and adults at 65 Japanese hospitals between 2001 and 2015. The mean patient age was 3.9 years, and mean weight was $12.5 \mathrm{~kg}$. The patients had a variety of congenital cardiac malformations requiring right $95.5 \%$ to 15 years.

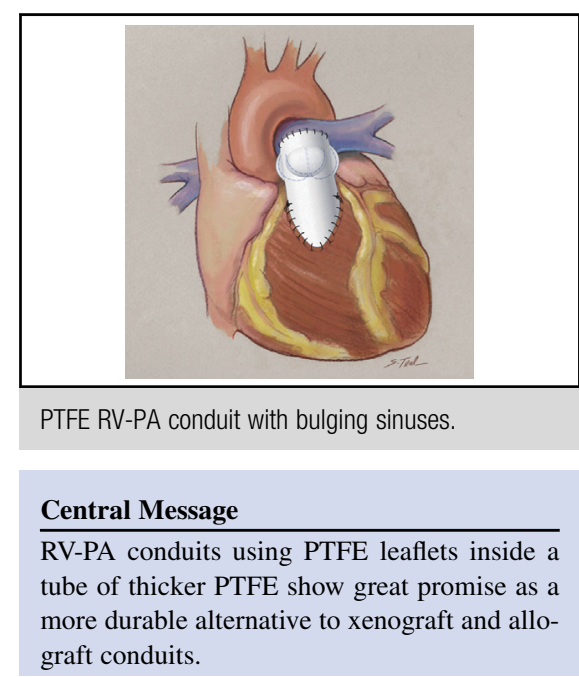

See Article page 2567.

ventricular outflow tract reconstruction. The patients' hospital survival was excellent at $98 \%$, and late survival was

They compared patients by age greater or less than 2 years of age. Those aged less than 2 years $(n=292)$ had a freedom from conduit replacement of $90 \%$ and $74 \%$ at 5 and 10 years, respectively. Freedom from conduit replacement in the group aged more than 2 years was greater than $95 \%$ at 10 years.

Their conduits showed excellent freedom from infection, stenosis, and regurgitation (>95\%) during follow-up (median, 4.8 years). Fifty-five conduits $(6 \%)$ were replaced mostly for outgrowth or stenosis proximal or distal to the valved conduit. Fifty-three patients required balloon catheter intervention for proximal or distal stenosis.

This large Japanese multicenter experience with a handmade conduit may not be immediately transferable to the United States and Europe because the Food and Drug Administration and other governing bodies are not likely to approve handmade valved conduits because of inconsistent quality control. The authors' experience is an excellent proof of concept and will open the door for industry to provide a consistent product for congenital heart surgeons.

PTFE valved conduits as shown in this article show real promise as an alternative to currently available RV-PA conduits. Longer follow-up will be necessary to see if these conduits continue to perform as well as the authors report. 


\section{Reference}

1. Miyazaki T, Yamagishi M, Maeda Y, Taniguchi S, Fujita S, Hongu H, et al. Longterm outcomes of expanded polytetrafluoroethylene conduits with bulging sinuses and a fan-shaped valve in right ventricular outflow tract reconstruction. J Thorac Cardiovasc Surg. 2018;155:2567-76.

2. Yamagishi M, Kurosawa H. Outflow reconstruction of tetralogy of fallot using a gore-tex valve. Annals of Thorac Surg. 1993;56:1414-6; discussion 1416-7. 